2. H. Kaplan, B. J. Sadock và Nguyễn Kim Việt (biên dịch) (2013), Rối loạn sự phát triển lạn tỏa, Tóm lược tâm thần học trẻ em và thanh thiếu niên - Nhà xuất bản y học.

3. Nguyễn Lan Trang (2012), "Thực trang RLPTK ở trẻ em tử 18-60 tháng tuổi tại Thành phố Thái Nguyên", Y hoc thức hành Số (851) 11/2012, tr. 29-32.

4. Blenner $S$ and $M$ Augustyn (2014), "Is the prevalence of autism increasing in the United States?", BMJ. 348, p. g3088.

5. Centers for Disease Control and Prevention (2012), "Prevalence of Autism Spectrum Disorders - Autism and Developmental Disabilities Monitoring
Network, 14 Sites, United States, 2008", Morbidity and Mortality Weekly Report. Surveillance Summaries. Volume 61, Number 3.

6. Icasiano F, P Hewson, P Machet, et al. (2004), "Childhood autism spectrum disorder in the Barwon region: a community based study", Journal of paediatrics and child health. 40(12), p. 696-701.

7. Schopler E, RJ Reichler, RF DeVellis, et al. (1980), "Toward objective classification of childhood autism: Childhood Autism Rating Scale (CARS)", Journal of autism and developmental disorders. 10(1), p. 91-103.

\title{
ĐÁNH GIÁ TÁC DUUNG CỦA NANO ALGINATE/CHITOSAN/LOVASTATIN LÊN RỐI LOẠN CHUYỂN HÓA LIPID TRÊN CHUộT CỐNG GÂY MÔ HÌNH BÉO PHÌ
}

\author{
Nguyễn Thị Hoa*, Nguyễn Lê Chiến*, Đinh Trọng Hà*, \\ Cấn Văn Mão*, Phạm Minh Đàm*
}

\section{TÓM TẮT}

Mục tiêu: Đánh giá tác dụng cải thiện rối loạn chuyển hóa Lipid máu của nano Alginate/Chitosan/ Lovastatin trên chuột cống trắng béo phì bằng thức ăn cao năng giàu chất béo. Đối tượng và phương pháp: 72 chuột cống đực trắng ở hai nhóm chế độ ăn thường $(n=36)$ và nhóm chế độ ăn cao năng giàu chất béo $(n=36)$. Sau giai đoạn gây mô hình béo phì 7 tuần được chia đều ngâu nhiển làm 6 nhóm gồm: 1) nhóm ăn chế độ thường-uống nước muối $(\mathrm{C}-\mathrm{NaCl}), 2)$ nhóm ăn chế độ thường-uống Lovastatin liều $4 \mathrm{mg} / \mathrm{kg}$ (C-Lovastatin), 3) nhóm ăn chế độ thường-uống tổ hợp nano Alginate/Chitosan// Lovastatin liêu $4 \mathrm{mg} / \mathrm{kg}$ (C-Nano/Lovastatin); 4) nhóm ăn chế độ giàu béouống nước muối (B-NaCl), 5) nhóm ăn chế độ giàu béo-uống Lovastatin liều $4 \mathrm{mg} / \mathrm{kg}$ (B-Lovastatin) và 6) nhóm ăn chế độ giàu béo-uống tổ hợp nano Alginate/Chitosan/Lovastatin liều $4 \mathrm{mg} / \mathrm{kg}$ (BNano/Lovastatin). Giai đoạn can thiệp kéo dài 12 tuần. Đo cân nặng, định lượng nồng độ triglycerid và cholesterol máu 3 tuân một lần, $H D L-C$ và $L D L-C$ trước và sau 12 tuần can thiệp. Kết quả: Về nồng độ các thành phần Lipid máu: Các nhóm chuột ở chế độ ăn thường không có sự khác biêt về nồng độ các thành phần lipid máu. Trong khi đó, các nhóm chuột ở chế độ ăn giàu béo có sự khác nhau về nồng độ triglycerid, cholesterol máu ( $p<0,05)$, trong đó nhóm B-Nano/Lovastatin giảm nồng độ triglycerid, cholesterol từ cuối tuần 6 đến cuối tuân 12 hơn so với nhóm $\mathrm{B}-\mathrm{NaCl}(\mathrm{p}<0,05)$, nhóm B-Lovastatin giảm nồng độ triglycerid, cholessterol từ cuối tuần 9 so hơn so với nhóm $\mathrm{B}-\mathrm{NaCl}(\mathrm{p}<0,05)$, nhóm B-Nano/ Lovastatin so với nhóm B-Lovastatin chưa có sự khác

*Hoc viên Quân y

Chịu trách nhiệm chính: Nguyễn Thị Hoa

Email: nguyenthihoahvqy@gmail.com

Ngày nhận bài: 2/6/2021

Ngày phản biên khoa học: 29/6/2021

Ngày duyệt bài: 20/7/2021 biệt với ( $p>0,05)$; không có sự khác biệt về nồng độ $\mathrm{HDL}-\mathrm{C}$ và $\mathrm{LDL}-\mathrm{C}$ trong huyết tương $(\mathrm{p}>0,05)$. Về trọng lượng cơ thể: Ớ chế độ ăn thường không có sự khác biệt giữa các nhóm. Ở chế độ ăn giàu béo, nhóm $\mathrm{B}-\mathrm{NaCl}$ có xu hướng tăng cân nhanh nhất sau đó đến nhóm B-Lovastatin và chậm nhất là nhóm $B$ Nano/Lovastatin nhưng chưa có sự khác biệt ( $p$ > 0,05). Kết luận: Từ các kết quả thu được cho thấy phức hợp alginate/chitosan/lovastatin làm tăng tác dụng của Lovastatin trong điều trị rối loạn lipid máu trền thức nghiệm.

Tư khóa: Chế độ ăn giàu chất béo, rối loạn lipid máu, chuột cống, alginate, chitosan, lovastatin.

\section{SUMMARY \\ EVALUATION OF THE EFFECTS OF NANO \\ ALGINATE/CHITOSAN/LOVASTATIN TO METABOLIC LIPID DISORDERS IN OBESITY RAT MODEL}

Objectives: Evaluate of the effect of improving lipid metabolism disorders of Alginate/Chitosan/Lovastatin nano in obese white rats by high-fat diet. Subjects and methods: The 72 white male rats were divided into two groups of normal diet $(n=36)$ and high-fat diet group $(n=36)$. After the 7-week of obesity model, these rats were randomly divided into 6 groups including 1 ) nomal diet-salt water (C-NaCl) group, 2) nomal dietlovastatin dose group $4 \mathrm{mg} / \mathrm{kg}$ (C-Lovastatin), 3) nomal diet- Alginate/Chitosan//Lovastatin nanocomposite $4 \mathrm{mg} / \mathrm{kg}$ (C-Nano/Lovastatin); 4) highfat diet-salt water $(\mathrm{B}-\mathrm{NaCl}), 5)$ high-fat diet-lovastatin dose of $4 \mathrm{mg} / \mathrm{kg}$ (B-Lovastatin) and 6 ) high-fat dietAlginate/Chitosan/Lovastatin nano combination at dose $4 \mathrm{mg} / \mathrm{kg}$ (B-Nano/Lovastatin). The intervention period is 12 weeks. Weight measurement examination of triglyceride and blood cholesterol levels every 3 weeks, HDL -C and LDL - C before and after 12 weeks of intervention. Results: About the concentration of blood lipid components: The groups 
of rats with the normal diet did not have any difference in the concentration of blood lipid components. Meanwhile, groups of rats on a high-fat diet (B - NaCl, B-Lovastatin and B-Nano/Lovastatin) had different concentrations of triglycerides and blood cholesterol ( $p<0.05)$, in which group B-Nano/ Lovastatin reduced the concentration of Triglyceride, Cholesterol from the end of week 6 to the end of week 12 more than the $\mathrm{B}-\mathrm{NaCl}$ group ( $p<0.05$ ), the BLovastatin group reduced the concentration of Triglyceride, Cholesterol more than from the end of week 9 compared with the $\mathrm{B}-\mathrm{NaCl}$ group ( $p<0.05$ ), there was no difference between the B-Nano/ Lovastatin group and B-Lovastatin with ( $p>0.05$ ); There was no difference in plasma HDL-C and LDL-C concentrations ( $p>0.05)$. About body weight: In the normal diet, there was usually no difference between the groups. In the high-fat diet, the $\mathrm{B}-\mathrm{NaCl}$ group tended to gain weight fastest, the B-Lovastatin group and the slowlest increase was the B-Nano/Lovastatin group, but there was no difference $(p>0.05)$. Conclusion: This study results showed that the alginate/chitosan/lovastatin increases the effect of Lovastatin in the treatment of dyslipidemia in the animals model.

Key words: High-fat diet, lipid disorders, rat, alginate, chitosan, lovastatin

\section{I. ĐĂT VẤN ĐỀ}

Theo Tổ chức $Y$ tế thế giới, thừa cân và béo phì là tình trạng tích lũy mõ quá mức hoặc không bình thường có thể ảnh hưởng đến sức khỏe [6]. Hiện nay, tình hình thừa cân, béo phì đang tăng lên với môt tốc độ đáng báo động ở nhiều quốc gia cả phát triển và đang phát triển, bao gồm cả Việt Nam [6]. Hậu quả của béo phì ảnh hưởng đển toàn bộ hệ thống các cơ quan trong cơ thể, trong đó có rối loạn chuyển hóa lipid và là nguyên nhân trực tiếp gây ra các bệnh tim mạch [5]. Vì vậy, điều trị sớm và triệt để các rối loạn chuyển hóa lipid máu có ý nghĩa quan trọng trọng dự phòng sớm các biến chứng tim mạch cho người bệnh.

Lovastatin là thuốc được chứng minh làm giảm nồng độ cholesterol hiệu quả trên lâm sàng. Tuy nhiên, thời gian bán thải của lovastatin tương đối ngắn, trung bình khoảng $3.7 \pm 3.8$ giờ, hấp thu kém qua đường tiêu hóa [2], [4], [5]. Những vấn đề này có thể ảnh hưởng nhất định đến hiệu quả điều trị của lovastatin. Sử dụng các thuốc giải phóng chậm là một trong những giải pháp giúp tăng hiệu quả điểu trị của thuốc được nghiên cứu trong thời gian gần đây. Ứng dụng công nghệ này, Viện Kỹ thuật nhiệt đới - Viện Hàn Lâm khoa học Việt Nam đã chế tạo thành công thuốc giải phóng chậm lovastatin bằng phức hợp nanoparticle tên là alginate/chitosan. Trong nghiên cứu này, chúng tôi tiến hành sử dụng phức hợp giải phóng chậm lovastatin trên động vật thực nghiệm nhằm mục tiêu: Đánh giá hiệu quả lên các thành phần Lipid máu của phức hợp Nano Alginate/chitosan/ Lovastatin trên thực nghiệm.

\section{II. ĐỐI TƯợNG VÀ PHƯƠNG PHÁP NGHIÊN CỨU}

2.1. Đối tượng nghiên cứu. 72 chuột cống đực trắng 8-9 tuần tuổi (cân nặng 100-150g) do Ban Động vật, Học viện Quân y cung cấp, ở hai chế độ ăn: nhóm ăn chế độ thường $(n=36)$ và nhóm ăn chế độ giàu chất béo $(n=36)$ sau giai đoan mô hình 7 tuần, được chia đều vào 6 nhóm (mối nhóm 12 con), bao gồm: i) nhóm ăn chế độ thường-uống nước muối (C-NaCl), ii) nhóm ăn chế độ thường-uống Lovastatin liều $4 \mathrm{mg} / \mathrm{kg}$ (C-Lovastatin), iii) nhóm ăn chế độ thường-uống tổ hợp nano Alginate/ Chitosan/Lovastatin liều 4 $\mathrm{mg} / \mathrm{kg}$ (C-Nano/Lovastatin); iv) nhóm ăn chế độ giàu béo-uống nước muối (B-NaCl), v) nhóm ăn chế độ giàu béo-uống Lovastatin liều $4 \mathrm{mg} / \mathrm{kg}$ (B-Lovastatin) và vi) nhóm ăn chế độ giàu béouống tổ hợp nano Alginate/Chitosan/Lovastatin liều $4 \mathrm{mg} / \mathrm{kg}$ (B-Nano/Lovastatin). Giai đoạn can thiệp kéo dài 12 tuần.

Động vật được nuôi trong điều kiện thoáng mát với chu kỳ sáng/tối là 12 giờ, thức ăn và nước uống không han chế và tuân thủ theo hướng dẫn chăm sóc và sử dụng động vật của Học viện Quân y.

\subsection{Phương pháp nghiên cứu}

2.2.1. Thiết kế nghiên cứu. Thiết kế nghiên cứu thực nghiệm, can thiệp ngẫu nhiên, có đối chứng, mô tả cắt ngang và theo dõi dọc.

2.2.2. Phương tiện, dụng cụ và hóa chất. Nguyên liệu thức ăn cho chuột do công ty Nutricare (Hà Đông, Hà Nội) cung cấp, được chế dưới dạng viên.

Cân điện tử để xác định trọng lượng chuột (độ chính xác đến mili gam), máy sinh hóa tự động và các kit cho xét nghiệm cholesterol và triglycerid. (Erba XL -180 - Đức).

Các hóa chất: Natri clorid 0,9\% (công ty Fresenius Kabi, Quy Nhơn, Bình Định), thuốc Lovastatin dạng bột (Sigma Aldrich), chế phẩm Nano Alginate/chitosan/Lovastatin với tỷ lệ 8:2:10\% Lovastatin, kích thước 50 - 80nm (Viện Kỹ thuật nhiệt đới, Viện Hàn Lâm Khoa học Việt Nam).

\subsection{Phương pháp nghiên cứu}

Các chỉ tiêu nghiên cứu: Trọng lượng, các chỉ số thành phần Lipid máu (triglycerid, cholesterol, $\mathrm{HDL}$ - cholesterol và $\mathrm{LDL}$ - cholesterol máu).

- Trong lượng của chuột (tính bằng gam): được xác định bằng cân Nhật Bản với độ chính xác đến 3 số 0 và được xác định trước can thiệp, cuối tuần $3,6,9$ và 12 can thiệp. 
- Nồng độ cholesterol, triglyceride, high density lipoprotein-cholesterol (cholesterol-HDL) và low density lipoprotein-cholesterol (Cholesterol-LDL) huyết tương: lây máu mạch máu hốc mắt, thể tích khoảng $2 \mathrm{ml}$ máu. Tiến hành ly tâm với tốc độ 5000 vòng/phút x 10 phút. Lấy phần dịch trong phía trên để định lượng nồng độ các loại lipid máu nói trên bằng máy sinh hóa tự động, xét nghiệm được thực hiện tại Viện nghiên cứu Y được học Quân sự, Học viện Quân y. Nồng độ cholesterol và triglyceride huyết tương được xác định ở các thời điểm trước điều trị, sau điều trị 3 tuần, 6 tuần, 9 tuần, và 12 tuần. Nồng độ cholesterol-HDL và cholesterol - LDL được xác định ở thời điểm trước điều trị và sau điều trị 12 tuần.

2.3. Xử lý số liệu. Sự khác biệt về cân nặng và lipid máu giữa các nhóm nghiên cứu được phân tích bằng phương pháp so sánh phương sai hai yếu tố có lặp (thời điểm nghiên cứu và nhóm nghiên cứu). Sự khác biệt có ý nghĩa thống kê được xác định với giá trị $\mathrm{p}<0,05$. Các số liệu trong nghiển cứu được biểu diễn dưới dạng trung bình $(\bar{x}) \pm S D)$.

2.4. Đạo đức nghiên cứu: Đúng quy trình chặt chẽ ban hành của Học viện Quân y.

\section{KẾT QUẢ NGHIÊN CứU}

\subsection{Trọng lượng của chuột}
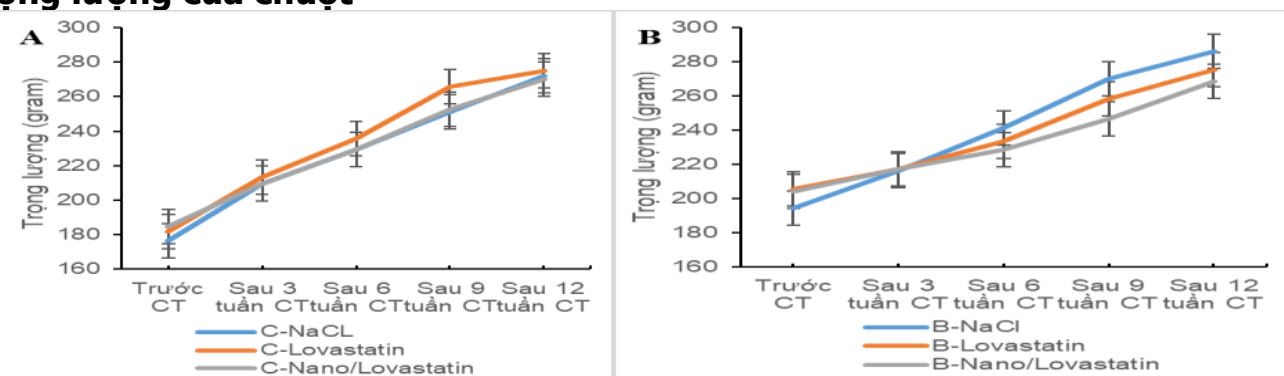

Hình 3.1. Trọng lượng (gram) của chuột ở chế độ ăn thường (A), ăn giàu béo (B) của các nhóm nghiên cứu qua 12 tuần can thiẹp.

Kết quả trên Hình $3.1 \mathrm{~A}$ và $3.1 \mathrm{~B}$ cho thây xu hướng tăng cân diễn ra ở cả sáu nhóm dùng dược chất của cả hai chễ độ ăn sau 12 tuần can thiệp. Ở chế độ ăn giàu béo sự tăng cân mạnh nhất là ở nhóm chứng $(\mathrm{B}-\mathrm{NaCl})$, tiếp sau là nhóm dùng Lovastatin ( $\mathrm{B}$-Lovastatin) và ít nhất là nhóm dùng phức hợp Nano/Lovastatin (B-nano/Lovastatin). Phân tích phương sai từng chế độ ăn với yếu tố

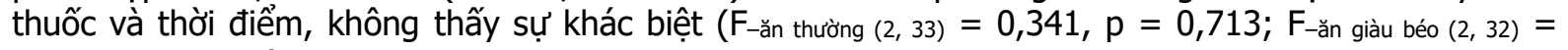
$0,379, p=0,688$ ).

\subsection{Nông độ các thành phân Lipid máu} thiệp.

Bảng 3.1. Nồng độ triglycerid máu (mmol/l) của chuột ở các nhóm nghiên cứu qua 12 tuần can

\begin{tabular}{|c|c|c|c|c|c|c|}
\hline \multicolumn{2}{|c|}{ Chố đôt ăn Thời điếm } & $\begin{array}{l}\text { Trước } \\
\text { CT }\end{array}$ & $\begin{array}{l}\text { Cuối tuần } \\
3 \text { CT }\end{array}$ & $\begin{array}{l}\text { Cuối tuần } \\
6 \text { CT }\end{array}$ & $\begin{array}{l}\text { Cuối tuần } \\
9 \text { CT }\end{array}$ & $\begin{array}{l}\text { Cuối tuần } \\
12 \text { CT }\end{array}$ \\
\hline \multirow{4}{*}{$\begin{array}{c}\text { Ăn } \\
\text { thường }\end{array}$} & C-Na & $1,17 \pm 0,70$ & $1,17 \pm 0,97$ & $1,43 \pm 0,63$ & $1,40 \pm 1,15$ & $1,19 \pm 1,18$ \\
\hline & \multirow{2}{*}{$\begin{array}{c}\text { C-Lovastatin } \\
\text { C-Nano/ } \\
\text { Lovastatin }\end{array}$} & $1,15 \pm 0,67$ & $0,90 \pm 0,54$ & $0,97 \pm 0,37$ & $0,88 \pm 0,50$ & $0,88 \pm 1,28$ \\
\hline & & $1,21 \pm 0,65$ & $0,82 \pm 0,40$ & $1,27 \pm 0,56$ & $0,84 \pm 0,63$ & $1,22 \pm 0,86$ \\
\hline & \multicolumn{6}{|c|}{ F-ăn thường $(2,33)=1,190, p=0,317$} \\
\hline \multirow{4}{*}{$\begin{array}{l}\text { Ăn } \\
\text { giàu } \\
\text { chất } \\
\text { béo }\end{array}$} & B-NaCl & $4,27 \pm 4,90$ & $1,51 \pm 1,48$ & $3,45^{a} \pm 1,71$ & $4,83^{b c} \pm 2,96$ & $2,54 \pm 2,88$ \\
\hline & \multirow{2}{*}{$\begin{array}{c}\text { B-Lovastatin } \\
\text { B-Nano/ } \\
\text { Lovastatin }\end{array}$} & $5,37 \pm 5,94$ & $1,15 \pm 0,71$ & $2,18 \pm 1,55$ & $2,07^{c} \pm 1,61$ & $1,40 \pm 1,37$ \\
\hline & & $2,92 \pm 2,21$ & $1,30 \pm 0,87$ & $1,98^{a} \pm 1,19$ & $1,13^{b} \pm 0,80$ & $1,35 \pm 0,97$ \\
\hline & \multicolumn{6}{|c|}{ 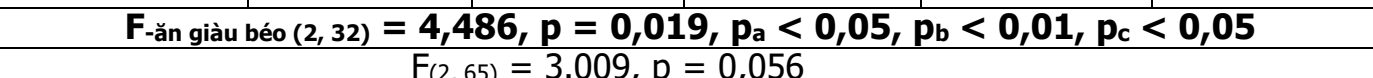 } \\
\hline
\end{tabular}

Kết quả trên Bảng 3.1 cho thấy nồng độ triglycerid máu của chuột ở cả hai nhóm chế độ ăn thường và ăn giàu chất béo có sự khác biệt nhất định khi sử dụng thuốc song chưa đat mức có ý nghĩa $(F(2,65)=3,009, p=0,056)$ (phân tích phương sai một chiều lặp). Phân tích kiểm định từng chế độ ăn cho thây ở nhóm ăn thường không có sự tương tác của các thuốc ( $\mathrm{F}$-ăn thường $(2$, 33) $=1,190, \mathrm{p}=0,317)$, trong khi ở nhóm ăn giàu chất béo có sự khác biệt có ý nghĩa thống 


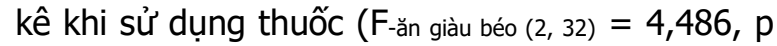
$=0,019$ ).

Kiểm đinh Bonferroni cho thấy ở chế đô ăn giàu chất béo: nồng độ triglycerid ở nhóm $\mathrm{B}$ Nano/Lovastatin có sự giảm khác biệt có ý nghĩa so với nhóm $\mathrm{B}-\mathrm{NaCl}(\mathrm{p}=0,016)$, không có sự khác biệt so với nhóm B-Lovastatin; nhóm BLovastatin và nhóm $\mathrm{B}-\mathrm{NaCl}$ chưa có sư khác biêt $(p>0,05)$. Phân tích sâu từng thời điểm cho thấy: sau 3 -6 tuần điều trị chưa có sự khác biệt giữa các nhóm; Sau 9 tuần điều trị, có sự khác nhau có ý nghĩa giữa nhóm $\mathrm{B}-\mathrm{NaCl}$ với nhóm BLovastatin $(\mathrm{p}=0,008)$ và nhóm $\mathrm{B}-\mathrm{NaCl}$ với nhóm B-Nano/Lovastatin $(p<0,01)$, không có sự khác biệt giữa hai nhóm B-Lovastatin với $B$ Nano/Lovastatin $(p>0,05)$; sau 12 tuần điều trị, không có sự khác biệt giữa cả 3 nhóm ( $p>$ $0,05)$.

Bảng 3.2. Nồng độ cholesterol máu (mmo/l) của chuột ở các nhóm nghiên cứu qua 12 tuần điều tri.

\begin{tabular}{|c|c|c|c|c|c|c|}
\hline \multicolumn{2}{|c|}{ Chế độ ăn } & Trước CT & $\begin{array}{l}\text { Cuối tuần } \\
3 \text { CT }\end{array}$ & $\begin{array}{l}\text { Cuối tuần } \\
6 \text { CT }\end{array}$ & $\begin{array}{l}\text { Cuối tuần } \\
9 \text { CT }\end{array}$ & $\begin{array}{l}\text { Cuối tuần } \\
12 \text { CT }\end{array}$ \\
\hline \multirow{4}{*}{$\begin{array}{c}\text { Ăn } \\
\text { thường }\end{array}$} & $\mathrm{C}-\mathrm{NaCl}$ & $1,29 \pm 0,18$ & $1,15 \pm 0,35$ & $1,29 \pm 0,25$ & $1,50 \pm 0,30$ & $0,95 \pm 0,46$ \\
\hline & C-Lovastatin & $1,21 \pm 0,45$ & $1,39 \pm 0,31$ & $1,11 \pm 0,33$ & $1,47 \pm 0,27$ & $1,08 \pm 0,49$ \\
\hline & $\begin{array}{l}\text { C-Nano/ } \\
\text { Lovastatin }\end{array}$ & $1,28 \pm 0,16$ & $1,21 \pm 0,22$ & $1,21 \pm 0,28$ & $1,38 \pm 0,53$ & $1,27 \pm 0,41$ \\
\hline & \multicolumn{6}{|c|}{ F-ăn thường $(2,33)=0,116, p=0,891$} \\
\hline \multirow{4}{*}{$\begin{array}{c}\text { Ăn giàu } \\
\text { chất } \\
\text { béo }\end{array}$} & $\mathrm{B}-\mathrm{NaCl}$ & $2,07 \pm 0,65$ & $1,45 \pm 0,63$ & $2,23^{a} \pm 0,59$ & $4,20^{\mathrm{bc}} \pm 3,21$ & $1,86^{\mathrm{d}} \pm 0,97$ \\
\hline & B-Lovastatin & $1,82 \pm 0,80$ & $1,43 \pm 0,23$ & $1,89 \pm 0,58$ & $1,69^{c} \pm 0,27$ & $1,33 \pm 0,36$ \\
\hline & $\begin{array}{l}\text { B-Nano/ } \\
\text { Lovastatin }\end{array}$ & $1,83 \pm 0,44$ & $1,45 \pm 0,13$ & $1,45^{\mathrm{a}} \pm 0,65$ & $1,50^{b} \pm 0,39$ & $1,14^{d} \pm 0,25$ \\
\hline & \multicolumn{6}{|c|}{$\begin{array}{c}\text { F-ăn giàu béo }(2,32)=6,831, p=0,004 ; p_{a}, p_{b}, p_{c}, p_{d}<0,05 \\
F_{(2,65)}=7,640, p=0,001\end{array}$} \\
\hline
\end{tabular}

Kết quả trên Bảng 3.2 cho thãy nồng độ cholesterol máu của chuột ở các nhóm chế độ ăn thường và ăn giàu chất béo có sự khác biệt có ý nghĩa khi sử dụng thuốc $\left(F_{(2,65)}=7,640, p=\right.$ $0,001)$. Phân tích ảnh hưởng của thuốc lên từng chế độ ăn cho thấy nhóm ăn thường không có sự khác biệt giữa các nhóm, trong khi ở nhóm ăn giàu chất béo có sự khác biệt có ý nghĩa khi sử

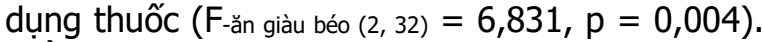
Kiểm định Bonferroni cho thây nồng độ cholesterol ở chế độ ăn giàu béo: nhóm $\mathrm{B}-\mathrm{NaCl}$ có sự khác biệt có ý nghĩa so với nhóm BLovastatin $(p=0,031)$ và nhóm $B-$ Nano/Lovastatin $(p=0,005)$; không có sự khác biệt giữa hai nhóm $B$-Lovastatin và nhóm $B$ Nano/Lovastatin $(p>0,05)$. Phân tích từng thời điểm cho thấy: sau 3 tuần điều tri chưa có sự khác biệt có ý nghĩa thống kê giữa các nhóm, nhưng đến thời điểm sau 6 tuần điều trị nhóm
B-Nano/Lovastatin có nồng đô cholesterol giảm khác biệt có ý nghĩa so với nhóm $\mathrm{B}-\mathrm{NaCl}$ ( $p=0,021)$; không có sự khác biệt giữa nhóm $B-$ $\mathrm{NaCl}$ với nhóm $B$-Lovastatin $(p>0,05)$ và giữa nhóm B-Lovastatin với B-Nano/Lovastatin ( $\mathrm{p}>$ 0,05); Sau 9 tuần điều trị có sự giảm khác biệt giữa nhóm $\mathrm{B}-\mathrm{NaCl}$ với nhóm $\mathrm{B}$-Lovastatin và nhóm B-Nano/Lovastatin $(p<0,05)$, chưa đạt sư khác biệt có ý nghĩa thống kê giữa nhóm $B$ Nano/Lovastatin và nhóm $B$-Lovastatin ( $p$ > $0,05)$; Sau 12 tuần điều trị, có sự giảm khác biệt giữa nhóm. B-Nano/Lovastatin với nhóm $\mathrm{B}-\mathrm{NaCl}$ ( $p=0,047)$, không có sự khác biệt giữa nhóm $B-$ Lovastatin với nhóm $\mathrm{B}-\mathrm{NaCl}$ và $\mathrm{B}-\mathrm{Nano} /$ Lovastatin $(p>0,05)$.

Kết quả về nồng độ $H D L$ và LDL-cholesterol máu của chuột ở các nhóm nghiên cứu qua 12 tuần can thiệp được trình bày trên các Bảng 3.3 và 3.4 .

Bảng 3.3. Nồng độ HDL-cholesterol máu (mmo/l) của chuột ở các nhóm nghiên cứu qua 12 tuần can thiệp.

\begin{tabular}{|c|c|c|c|c|}
\hline \multicolumn{2}{|c|}{ Chế độ ăn Dược chất } & $\mathbf{N a C l}$ & Lovastatin & Nano/Lovastatin \\
\hline \multirow{2}{*}{ Ăn thường } & Trước CT & $0,92 \pm 0,18$ & $1,02 \pm 0,30$ & $0,91 \pm 0,24$ \\
\hline & Sau 12 tuần $\mathrm{CT}$ & $0,74 \pm 0,19$ & $0,71 \pm 0,27$ & $0,78 \pm 0,22$ \\
\hline \multicolumn{5}{|c|}{ F-ăn thường $(2,33)=0,188 \mathrm{p}=0,829$} \\
\hline \multirow{2}{*}{$\begin{array}{c}\text { Ān giàu chất } \\
\text { béo }\end{array}$} & Trước CT & $0,86 \pm 0,41$ & $0,57 \pm 0,37$ & $0,87 \pm 0,36$ \\
\hline & Sau 12 tuân CT & $0,79 \pm 0,31$ & $0,65 \pm 0,31$ & $0,85 \pm 0,17$ \\
\hline \multicolumn{5}{|c|}{ 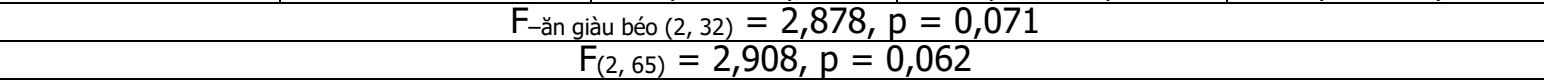 } \\
\hline
\end{tabular}

Kết quả trên Bảng 3.3 cho thấy nồng độ HDL-cholesterol máu của chuột ở các nhóm chế độ ăn 
thường và ăn giàu chất béo khi sử dụng thuốc có khác biệt song chưa đạt mức có ý nghĩa $\left(\mathrm{F}_{(2,65)}=\right.$ $2,908, p=0,062$ ).

Bảng 3.4. Nồng độ $L D L$-cholesterol máu (mmo/I) của chuột ở các nhóm nghiên cứu qua 12 tuần can thiệp.

\begin{tabular}{|c|c|c|c|c|}
\hline \multicolumn{2}{|c|}{ Chế độ ăn Dược chất } & NaCL & Lovastatin & Nano/Lovastatin \\
\hline \multirow{2}{*}{ Ăn thường } & Trước CT & $0,57 \pm 0,11$ & $0,60 \pm 0,16$ & $0,57 \pm 0,10$ \\
\hline & Sau 12 tuần CT & $0,53 \pm 0,09$ & $0,51 \pm 0,12$ & $0,53 \pm 0,21$ \\
\hline \multicolumn{5}{|c|}{ F-ăn thường $(2,33)=0,018, p=0,982$} \\
\hline \multirow{2}{*}{$\begin{array}{l}\text { Án giàu chất } \\
\text { béo }\end{array}$} & Trước CT & $1,04 \pm 0,45$ & $1,02 \pm 0,60$ & $0,84 \pm 0,27$ \\
\hline & Sau 12 tuần CT & $0,70 \pm 0,31$ & $0,60 \pm 0,13$ & $0,60 \pm 0,21$ \\
\hline \multicolumn{5}{|c|}{ 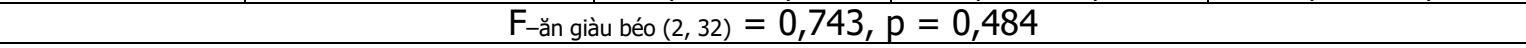 } \\
\hline & & $65)=0,708, p$ & & \\
\hline
\end{tabular}

Kết quả trên Bảng 3.4 cho thấy nông độ LDL-cholesterol máu của chuột ở cả hai nhóm chế độ ăn thường và ăn giàu chất béo không có sự khác biệt khi sử dụng thuốc $\left(\mathrm{F}_{(2,65)}=0,708, \mathrm{p}=0,496\right)$.

\section{BÀN LUẬN}

Về trọng lượng, nhóm can thiệp ở chế độ ăn thường không có thay đổi trong suốt 12 tuần can thiệp. Trong khi đó, nhóm gây béo phì bằng chế độ ăn giàu chất béo, trọng lượng chuột của nhóm chứng dùng nước muối sinh lý có xu hướng tăng cân nhiều nhất, sau đến nhóm điều trị bằng Lovastatin và tăng ít nhất là nhóm điều trị bằng tổ hợp nano/Lovastatin. Điều này phù hợp với những nghiên cứu gân đây cho thấy phức hợp nano Alginate/chitosan/Lovastatin được cấu tạo gồm một nanoparticle là tổ hợp Alginate/Chitosan và Lovastatin vừa có vai trò như chất mang, kiểm soát quả trình hấp thu, giải phóng của thuốc [7] vừa có tác dụng giảm hoặc làm chậm quá trình tăng cân trên động vật thực nghiệm [3], [7]. Chính nhờ sự phối hợp của nanoparticle và Lovastatin đã làm tăng hiệu quả của điều trị của thuốc

Về đánh giá hoạt động chuyển hóa lipid huyết tương, kết quả nghiên cứu này cho thấy nồng độ cholesterol và triglycerid huyêt tương không thay đổi trước và sau điều trị và giữa các nhóm nghiên cứu ở chế độ ăn thường, nhưng ở chế độ ăn giàu chất béo lại có sự khá biệt. Cụ thể, trong nhóm béo phì, tăng lipid máu: nhóm ( $B$ Nano/Lovastatin) có nồng độ cholesterol huyết tương giảm có ý nghĩa thống kê từ tuần 6 và nồng độ triglycerid cũng xu hướng giảm ở tuần 6 và có ý nghĩa thống kê vào tuần 9 cà nhóm $(B$ Lovastatin) có nồng độ cholesterol và triglycerid huyết tương giảm có ý nghĩa thống kê ở tuần 9 so với nhóm (B-NaCl). Tương tự như kết quả ghi nhận trong nghiên cứu hiện tại của chúng tôi, một số nghiên cứu cho thấy Lovastatin có tác dụng chủ yếu làm giảm cholesterol huyết tương [1], [7] song cũng có nghiên cứu cho thây Lovastatin có tác dụng làm giảm manh với nồng độ triglycerid máu [2]. Chú ý rằng nồng độ triglycerid máu có ảnh hưởng rất lớn từ chế đô ăn, điều đó có thể phần nào ảnh hưởng đên kết quả giảm triglycerid huyết tương khi được điều trị bẳng Lovastatin và nanochitosan/Lovastatin trong nghiên cứu hiện tại. Đây có thể cũng là một vấn đề mở mà chúng tôi cần tiếp tục thực hiện các nghiên cứu sâu hơn trong tương lai.

Phân tích sự thay đổi nồng độ $\mathrm{HDL}$ cholesterol và LDL-cholesterol trong máu cần thiết nhằm đánh giá nguy cơ của các bệnh lý như vữa xơ động mạch... trên bệnh nhân có rối loạn chuyển hóa lipid, đặc biệt rối loạn chuyển hóa trong béo phì [4]. Kết quả nghiên cứu của chúng tôi cho thây sự thay đổi nồng độ $\mathrm{HDL}$ cholesterol trước và sau điều trị và giứa các nhóm điều trị không có sự khác biệt. Trong khi đó, nồng đô LDL-cholesterol có giảm sau điều trị ở cả ba nhóm, nhưng không có sư khác biêt có ý nghĩa thống kê giữa các nhóm. Kết quả nghiên cứu của chúng tôi khác so với một số nghiên cứu trước đây về tác dụng của Lovastatin lên rối loạn chuyển hóa lipid [2]. Sự khác này có thể do số lượng chuột, giống chuột cũng như điều kiện nuôi và xét nghiệm... và tuy chưa làm rõ được hiệu dụng của Lovastatin đơn thuần và có chất mang nano lên các thành phần $\mathrm{HDL}$ và $\mathrm{LDL}$ cholesterol, song kết quả cũng có cho thấy xu hướng làm giảm LDL-cholesterol, tức làm giảm "cholesterol xấu".

\section{KẾT LUÂ̂N}

Từ các kết quả thu được cho thấy phức hợp alginate/chitosan/lovastatin làm tăng tác dụng của Lovastatin trong điêu trị rối loạn lipid máu trên thực nghiệm.

Lời cảm ơn. Chúng tôi cám ơn Viện kỹ thuật nhiệt đới - Viện Hàn Lâm khoa học Việt Nam, Trung tâm $Y$ dược học Quân sự và Bộ môn Sinh lý học (Học viện Quân y) đã giúp đỡ chúng tôi 
thực hiện nghiên cứu này.

\section{TÀI LIỆ THAM KHẢO}

1. A multicenter comparison of lovastatin and cholestyramine therapy for severe primary hypercholesterolemia. The Lovastatin Study Group III. (1988). The Journal of the American Medical Association, 360(3):359-366.

2. Bradford R.H., Shear C.L., Chremos A.N., et al. (1991). Expanded Clinical Evaluation of Lovastatin (EXCEL) study results. I. Efficacy in modifying plasma lipoproteins and adverse event profile in 8245 patients with moderate hypercholesterolemia. Archives of Internal Medicine, 151:43-49.

3. Daniel I Swerdlow, David Preiss, Karoline B Kuchenbaecke, et al. (2015). HMG-coenzyme A reductase inhibition, type 2 diabetes, and bodyweight: evidence from genetic analysis and randomised trials. Lancet, 385(9965): $351-361$.

4. Hernáez A., Soria-Florido M.T., Schröder H. et al. (2019). Role of HDL function and LDL atherogenicity on cardiovascular risk: A comprehensive examination. PLoS One, 14(6):e0218533.

5. Krukemyer J.J., Talbert R.L. (1987). Lovastatin: A new cholesterol-lowering agent. Pharmacotherapy 7:198-210.

6. World Health Organisation. Obesity and overweight. 1 April 2020; <https:// www.who.int/en/news-room/fact-sheets/detail/ obesity-and-overweight> Accessed on August 5, 2020.

7. Wilczewska A.Z., Niemirowicz K., Markiewicz K.H., et al. (2012). Nanoparticles as drug delivery systems. Pharmacological reports: PR, 64(5):10201037.

\section{NGHIÊN CỨU PHÂN LÂP VÀ XÁC ĐINHH HỢP CHẤT CẦN SA TỔNG HỢP 5-FLUORO-MDMB-PICA TRONG CÁC MẪU TANG VÂT THU TẠI VIỆT NAM TỪ 2018 - 2020}

\section{TÓM TẮT}

Muc tiêu: Phân lập và tinh khiết hóa hợp chất 5FLUOROO-MDMB-PICA dùng làm chất chuẩn định tính và định lượng. Đối tượng và phương pháp: Mẫu cần sa tổng hợp chứa trong các dạng có Mỹ được thu thâpp trong các vu án tại Việt Nam từ năm 2018 đến 2020, được chiết nóng nhanh với dicloromethan ở nhiệt độ $40^{\circ} \mathrm{C}$ để thu được cao dicloromethan. Cao dicloromethan toàn phần được tiến hành phân lập bằng sắc ký cột để thu được hợp chất 5-FLUOROMDMB-PICA. Kết quả: Từ $10 \mathrm{~g}$ cao dicloromethan toàn phần, sau phân lập thu được $0,9 \mathrm{~g}$ hợp chất 5FLUORO-MDMB-PICA với đô tinh khiết 99,46\% trên HPLC-PDA. Cấu trúc của hợp chất 5-FLUORO-MDMBPICA đã được xác đinh dựa trên các phương pháp phân tích TLC, IR, UV, GC-MS, LC-MS, NMR. Kêt luận: Nghiên cứu đã phân lập và tinh khiết hóa thành công hợp chất 5-FLUORO-MDMB-PICA định hướng thiết lập làm chất đối chiếu phục vụ cho công tác kiểm nghiệm, giám định các mẫu cần sa tổng hợp, đáp ứng yêu cầu công tác điều tra tôi pham ma túy tai Viêt Nam.

Từ khóa: Cần sa tổng hợp, 5-FLUORO-MDMBPICA, sắc ký cột, HPLC-PDA.

\section{SUMMARY \\ ISOLATION AND IDENTIFICATION OF THE SYNTHETIC CANNABINOID 5-FLUORO-}

\footnotetext{
*Đại học Y Dượ TP Hồ Chí Minh

**Phân viên Khoa hoc hình sư TP HCM

Chịu trách nhiệm chính: Nguyễn Hùng Cường

Email: hungcuongkndc@gmail.com

Ngày nhận bài: 15/5/2021

Ngày phản biên khoa hoc: 8/6/2021

Ngày duyệt bài: 15/7/2021
}

Nguyễn Hùng Cường*, Nguyễn Đăng Tiến**

\section{MDMB-PICA IN CRIMINAL EVIDENCES IN} VIETNAM IN THE PERIOD OF 2018 - 2020

Objectives: Isolation, purification, and structural elucidation of 5 - FLUORO - MDMB - PICA compound to be used as a reference standard. Methods: Synthetic cannabis samples contained in American grass collected in criminal cases in Vietnam from 2018 to 2020, were rapidly hot-extracted with dichloromethane at $40 \mathrm{oC}$ to obtain total dichloromethane extract. Then, the total dichloromethane extract was separated by column chromatography to collect 5 - FLUORO - MDMB - PICA. Results: $0,9 \mathrm{~g}$ of 5 - FLUORO - MDMB - PICA was collected from $10 \mathrm{~g}$ of total dichloromethane extract with the purity of $99,46 \%$. The structure of 5 FLUORO - MDMB - PICA compound was elucidated by analytical methods TLC, IR, UV, GC-MS, LC-MS, NMR. Conclusions: In the study, 5-FLUORO-MDMB-PICA compound has been successfully isolated, purified, and structural elucidated. The compound could be potentially used as a reference standard for testing and assessing synthetic cannabis samples, meeting the requirements of investigating drug crimes in Vietnam.

Key words; Synthetic cannabinoids, 5 - FLUORO MDMB - PICA, column chromatography, HPLC-PDA

\section{I. ĐĂTT VẤN ĐỀ}

Ma túy truyền thống như thuốc phiện, heroin được sử dụng phổ biến với những dấu hiệu nghiện điển hình như mệt mỏi, suy giảm về thể trạng, trí óc. Tuy nhiên, hiện nay ở Việt Nam, xuất hiện nhiều loại ma túy mới thuộc nhóm cần sa tổng hợp (Synthetic Cannabinoids) với tác dụng nhanh và mạnh hơn nên được giới trẻ ưa 